\title{
Knowledge Building through Multiple Literacy Learning
}

\author{
Karen Bonanno \\ Executive Officer \\ Australian School Library Association \\ PO Box 5689 \\ Mackay MC Queensland 474I \\ Australia \\ asla@asla.org.au
}

\begin{abstract}
In the 'knowledge society' increasing emphasis is being placed on independent, resource-based and technology-based inquiry learning. This learning process requires teacher librarians/library media specialists and their teaching teams to have access to an expanding range of curriculum information and teaching/learning methodologies. An outcomes approach to learning in regard to a sequential, developmental and progressive learning of information literacy skills within an information processing framework has been on the agenda and actively pursued by teacher librarians/library media specialists for more than a decade. In addition, teacher librarians/library media specialists have embraced information and communication technologies (ICT) as a means to extend the information literacy skills of their learners. An information skills framework becomes the backbone and 'vehicle' through which learners are able to demonstrate what they know and can do within an outcomes-based curriculum. This inquiry approach is the 'linch-pin' across the curriculum. Combine this with a recognized information skills, and information and communication technology (ICT) continuum, one has the beginnings of a progressive and development outcomes curriculum, which works on increasing levels of sophistication and complexity of tasks. In planning a unit of work the information skills framework provides the backbone to sequence the learning activities according to an inquiry-based approach. The tools and methodologies one uses to activate learning within this framework encourages and fosters the development of information literacy attributes and provides opportunity to engage in ICT skills development. School based planning of information literacy in conjunction with an outcomes approach to the curriculum facilitates an informative reporting process for students, as well as parents, as learners continue the journey through lifelong learning in the 'knowledge society'.
\end{abstract}

\section{Background - Four Pillars of Education and beyond}

Back in the mid 1990's I was thrilled to stumble across the 'four pillars of education' as agreed upon by the International Commission of Education for the Twenty-first Century in their report Learning: the Treasure Within. Simply, education throughout life is based upon four pillars:

- "learning to know,

- learning to do,

- learning to live together and 
- learning to be." (UNESCO)

I see these strongly reflected in the outcomes approach to education as experienced in Australian schools.

'Learning to know' focuses on the need to incorporate the new and emerging sources of information. The skills of knowledge-workers are challenged and stretched to deliver information in multimedia formats to meet the needs of various modes of learning in a networked world. Learning to learn makes the most of a multi-sensory approach. It focuses on an understanding of what one needs to know, how one gets to know and who does the knowing/learning. The content will be ever changing, the process of learning will be crucial and even complex and each learner's needs will be different.

'Learning to do' facilitates the link between knowledge and skills, learning and competencies, thinking and processes. Learning by doing and doing by learning triggers the problem solving and solution creation skills required by our youth to face the challenges of the changing nature of work and the world. It helps them prepare for change, decide on and contribute to their future.

'Learning to live together' provides the challenge for our time in a global world to overcome division and build community, to identify and construct international citizenship.

'Learning to be' emerges as the metaphysical pursuit of humankind.

\section{Background - the Australian scene}

A new set of Australian national goals for schooling in the $21^{\text {st }}$ Century was released in April 1999 as The Adelaide Declaration (which supersedes The Hobart Declaration.) These goals reflect the necessity for "future Australians to have the necessary knowledge, understanding, skills and values for a productive and rewarding life in an educated, just and open society". (Adelaide Declaration: 1999)

The national goals incorporate the principles of the four pillars of education to develop a holistic approach in that the role of schooling is to provide the foundation for mental, social, physical and spiritual development.

An outcomes approach to learning focuses on outputs rather than inputs. It is based on a belief that there are certain things all students should learn. These 'things' they should know are the core learning outcomes. They are the 'things' they need to be familiar with, that are important and essential to know. The discretionary learning outcomes are those that take a learner to a deeper understanding, to an outcome that results from an application of higher order thinking, for example. This belief then directs planning and assessment throughout the curriculum.

Learning in an outcomes curriculum is progressive and developmental. It works on increasing levels of sophistication and complexity of tasks. As learners progress through the stages of the continuum they are seen to be moving towards the desired learning and achieving the 'things all students should learn'. For the learner it establishes a sense of purpose, a target to be reached, a goal to be attained as the expectation is set to what they will come to know and be able to do. The continuum provides learners with signposts to point the way ahead, provide direction and link learning to assessment. The intention is for learners to 
progress from one level to the next level in a seamless, continuous, coherent way through productive opportunities to learn and do.

Assessment provides opportunities for learners to demonstrate their knowledge, skills, abilities and processes. It asks students what they know, what they are able to do and how they are able to do it. Within this outcomes approach there is also acknowledgement that there are

- different ways to learn(e.g. multi-sensory, multi-media)

- different rates of learning(e.g. chronological age and/or year/grade level do not equal learning age) and

- different learning environments(e.g. face-to-face, distance education, real-life, just-intime)

\section{Information Skills Continuum and beyond}

An outcomes approach to learning in regard to the sequential, developmental, progressive learning of information skills within an information process/framework has been on the agenda and actively pursued by teacher librarians in Australia for more than a decade. Even before the release of the national curriculum profiles for the key learning areas in 1994 teacher librarians across the nation where producing continua as supporting documentation for the services offered by the resource centre and its staff. Teacher librarians were already focusing on levels of attainment/achievement as progressive stages through a process of learning towards becoming information literate. Over time this has expanded to accommodate the advances in information and communication technologies, increased globalisation of learning and different learning environments.

In 1993 the Western Australia Department of Education produced a draft document, Information skills continuum, which combined learning outcomes from all the key learning areas into a generic set of learning outcomes which specifically reflected the developmental process of information skills development. Levels 1 to 6 were developed for each of the stages of the information process as presented in Learning for the future: developing information services for Australian schools. Indicators were developed for each level and outcome, which would guide teachers and teacher librarians to identify what to look for as demonstrated evidence of competence.

The national professional association representing teacher librarians, the Australian School Library Association (ASLA), applied for the copyright release of the above draft document to include in the multimedia CD-ROM, Teaching Information Skills: Professional development CD-ROM. The draft material was massaged, reviewed and adjusted to accommodate the eight national curriculum profile documents released in 1994 for all Australian schools. The information process continuum: levels of skills development documentation became an integral and crucial component of the multimedia CD-ROM in the Case Studies section. Samples of work produced by learners in each case study were placed against the outcomes and indicators to assess/evaluate the level of performance. The CD$\mathrm{ROM}$, as in an outcomes approach, demonstrates there are

- different ways of learning

- different rates of learning, and

- different learning environments. 
With the global release of the CD-ROM in 1997 it was evident that the inclusion of information skills in many of the strands in the curriculum profiles indicated an importance being placed on an inquiry approach to learning.

The planning overviews of Ryan and Capra (1999) and the current revision of Learning for the future: developing information services in Australian schools continues to add to and enhance the outcomes based approach to information skill development across the key learning areas.

Following the release of the national curriculum profiles for Australian schools many states and territories published their own documentation. Since 1994 there has been a lot of rework resulting in state/territory specific syllabus/curriculum direction for an outcomebased result. The rework has resulted in an even stronger emphasis on inquiry based learning across and within the key learning areas. Teacher librarians can choose to develop a schoolbased outcomes approach to information skill development (including information \& communication technology), e.g. an information skills continuum, and/or familiarise themselves with the outcomes, as documented in each key learning area, that link to an information skills framework.

\section{Structured approach for Queensland (Australia)}

Each key learning area within the Queensland school curriculum is designed to support a lifelong learning process. The valued attributes of a lifelong learner within the Queensland curriculum are:

- "a knowledgeable person with deep understanding;

- a complex thinker;

- a creative person;

- an active investigator;

- an effective communicator;

- a participant in an interdependent world;

- a reflective and self-directed learner." (SOSE: 2000: 4)

I firmly believe these attributes have been and are the 'playing field' of teacher librarians and open the door of opportunity to continue to be proactive in the development of outcomes-based units of work. A typical structure for the planning of a unit may be as follows:

\begin{tabular}{|l|}
\hline 1. Select a title / topic \\
\hline 2. Identify the core learning outcomes to be demonstrated \\
\hline 3. Develop a purpose for the unit, i.e. why are the students doing it? \\
\hline 4. Identify appropriate content / contexts \\
\hline 5. Identify what students are expected to know and do as a result of the unit \\
\hline 6. Identify possible activities and resources/tools, i.e. effective teaching and learning \\
\hline $\begin{array}{l}\text { 7. Sequence the activities according to an inquiry-based approach, i.e. expanded } \\
\text { information skills framework (an across the curriculum approach which } \\
\text { integrates Working Scientifically, Social and Environmental inquiries, etc) }\end{array}$ \\
\hline 8. Develop assessment tasks and criteria \\
\hline 9. Plan evaluation
\end{tabular}

(Modified version of unit planning model - HPE: 2000: 92) 
This structure continues to facilitate the co-operative planning process involving the teacher, teacher librarian and, where necessary, other teaching personnel. All parties need to be familiar with the outcomes and be willing to engage in shared learnings when it comes to planning teaching and learning methodologies, tools and resources. Step 7 allows for joint ownership of the information skills process and begins to familiarise the learner with the framework as well. The teaching of information skills (including information \& communication technology skills) in context across all key learning areas allows for the skills to be constantly reinforced. In time, the skills and the process become an accepted part of the students' learning strategies. Hence, the attributes of lifelong learning, as outlined above, can be addressed within this structure.

Should learners 'fall below' the level assigned to the unit of work, the teacher librarian is strategically placed to assist with, for example,

- extra activities,

- opportunities to develop understanding of the purpose and content,

- different learning and teaching approaches,

- alternate ways to explain expectations,

- a variety of learning activities and

- the completion of assessment tasks.

\section{Outcomes of outcomes}

"Today education is heralded as fundamental to public policy: fundamental to social cohesion, to economic development, to sustainable competitiveness, to human advancement, to the construction of world peace." (Carneiro: 1998)

An outcome-based curriculum helps to fulfil the commission of the UNESCO report and the national goals of The Adelaide Declaration.

It allows learners to

- experience personal and academic success and excellence as it recognises and accommodates difference

- understand and confidently utilise new and emerging technologies as information and communication tools through continued opportunities to know and do

- expand and improve their knowledge and skill base by progressive and developmental achievement as a means of empowerment

- develop and broaden their learning styles and modes through a variety of activities which demonstrate what they know and do

- recognise, acknowledge and accommodate cultural diversity, collaborative communities, global citizenship and the importance of interdependence through a broad base of curriculum strands

- understand and apply accumulated knowledge, skills, abilities and processes to attain personal, social and economic sustainability. 


\section{Leverage}

Outcomes-based education represents a "recognition that teachers are central to education and that any sustainable approach to educational change stands little chance of success without the full support and active participation of teachers." (Carneiro: 1998)

The active participation of teacher librarians in the development of outcome-based units of work continues to play out the certainty of what we do well. The paradox is that there may be moments of uncertainty as we grapple with the challenge and variety an outcomes approach may provide. Even so, teacher librarians who have diligently explored and addressed their continuing professional development needs are well positioned and even well connected to resource and service an outcomes-based curriculum. We are on our own continuum of lifelong learning, progressing through stages and levels of competency and achievement, set by us and/or others, to demonstrate what we know, what we can do and how we did it.

\section{REFERENCES}

Carneiro, Roberto (Professor) (1998). Learning: the Treasure Within - a Guided Tour. Online. http://www.sofweb.vic.edu.au/news/unesconf/

Health and physical education: Initial in-service materials. (2000). Brisbane: Queensland School Curriculum Council.

Information skills continuum: Draft. (1993). Perth: Western Australian Ministry of Education.

Learning for the future: developing information services in Australian schools. (1993). Melbourne: Curriculum Corporation.

Ryan, Jenny \& Capra, Steph (1999). ILPO: information literacy planning overview P/K-7. Revised edition. Capalaba, Brisbane: Capra Ryan \& Associates.

Ryan, Jenny \& Capra, Steph (1999). ILPO: information literacy planning overview 8-12. Capalaba, Brisbane: Capra Ryan \& Associates.

Studies of society and environment Years 1 to 10 syllabus with Years 9 and 10 optional subject syllabuses. (2000). Brisbane: Queensland School Curriculum Council.

Teaching information skills: Professional development CD-ROM. (1997). Belconnen, ACT: Australian School Library Association.

The Adelaide Declaration on National Goals for Schooling in the Twenty-First Century. Online. http://www.curriculum.edu.au/mceetya/nationalgoals/

UNESCO Task Force on Education for the Twenty-first Century. Online. http://www.unesco.org/delors/ 